\title{
Erratum to: Genetically-controlled Vesicle-Associated Membrane Protein 1 expression may contribute to Alzheimer's pathophysiology and susceptibility
}

\author{
Daniel Sevlever ${ }^{1 \dagger}$, Fanggeng Zou ${ }^{1,2+}$, Li Ma', Sebastian Carrasquillo ${ }^{1}$, Michael G. Crump${ }^{1}$, Oliver J. Culley ${ }^{1}$,
}

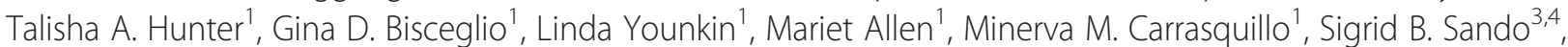
Jan O. Aasly ${ }^{4}$, Dennis W. Dickson ${ }^{1}$, Neill R. Graff-Radford ${ }^{5}$, Ronald C. Petersen ${ }^{6}$, Ferenc Deák ${ }^{1,7}$, Kevin Morgan for ARUK consortium ${ }^{8}$ and Olivia Belbin ${ }^{1,9^{*}}$

\section{Erratum}

Following publication of this work [1], we noticed that we inadvertently failed to include Dr Ferenc Deák in the author list. The author list has now been corrected and the amended authors' contributions section has been modified accordingly below.

\begin{abstract}
Authors' contributions
DS was responsible for generation and maintenance of the mouse models, shRNA knockdown and neuronal cultures, assisted in the data analysis and manuscript writing. FZ participated in the design of the study, was responsible for the TaqMan low-density array of VAMP1 transcripts, genotyping and assisted in the data analysis and manuscript writing. LM was responsible for the maintenance of the DNA samples, assisted in the genotyping and AB ELISA. SC assisted in the generation and maintenance of the mouse models, shRNA knockdown and neuronal cultures. MC performed the genotyping and dual luciferase assay for rs7390. OJC performed the dual luciferase assay for rs 12964 and rs2072376. TAH supervised the genotyping of VAMP1. GB assisted in the maintenance of the DNA samples and genotyping. LY and MA performed the AB ELISA. MMC participated in the design of the study, assisted in the genotyping and data analysis. SBS and JOA provided DNA samples for the study. DWD, NRG-R and RP provided DNA samples for the study as well as clinical and postmortem diagnoses. FD played a key role in the conception and design of the study. KM for the ARUK consortium provided DNA samples for the study, participated in the design of the study. OB participated in the design of the study, supervised the dual luciferase assay, and was responsible for the data analysis and writing of the manuscript. All authors critically revised the manuscript, gave final approval for submission and agree to be accountable for all aspects of the work in ensuring that questions related to the accuracy or integrity of any part of the work are appropriately investigated and resolved.
\end{abstract}

\footnotetext{
* Correspondence: obelbin@santpau.cat

${ }^{\dagger}$ Equal contributors

'Department of Neuroscience, Mayo Clinic College of Medicine, Jacksonville, FI 32224, USA

${ }^{9}$ Memory Disorders Unit, Institute of Biomedical Investigation Sant Pau (IIB Sant Pau), Autonomous University of Barcelona (UAB), Barcelona, Spain Full list of author information is available at the end of the article
}

\section{Author details}

Department of Neuroscience, Mayo Clinic College of Medicine, Jacksonville, FI 32224, USA. ${ }^{2}$ Human Genetics Division, Cincinnati Children's Hospital Medical Center, Cincinnati, OH 45229, USA. ${ }^{3}$ Department of Neurology, St. Olav's Hospital, Edvard Griegs Gate 8, 7006 Trondheim, Norway. ${ }^{4}$ Department of Neuroscience, Norwegian University of Science and Technology, NTNU, 7491 Trondheim, Norway. ${ }^{5}$ Department of Neurology, Mayo Clinic College of Medicine, Jacksonville, FI 32224, USA. ${ }^{6}$ Department of Neurology and the Mayo Alzheimer Disease Research Center, Mayo Clinic College of Medicine, Rochester, MN, USA. ${ }^{7}$ Reynolds Oklahoma Center on Aging, Department of Geriatric Medicine, University of Oklahoma HSC, Oklahoma City, OK 73104 USA. ${ }^{8}$ School of Molecular Medical Sciences, Institute of Genetics, Queen's Medical Centre, University of Nottingham, Nottingham, UK. ${ }^{9}$ Memory Disorders Unit, Institute of Biomedical Investigation Sant Pau (IIB Sant Pau), Autonomous University of Barcelona (UAB), Barcelona, Spain.

Received: 18 September 2015 Accepted: 18 September 2015 Published online: 23 September 2015

\section{Reference}

1. Daniel S, Fanggeng Z, Li M, Sebastian C, Crump MG, Culley OJ, et al. Genetically-controlled Vesicle-Associated Membrane Protein 1 expression may contribute to Alzheimer's pathophysiology and susceptibility. Mol Neurodegener. 2015:10:18.

\section{Submit your next manuscript to BioMed Central and take full advantage of: \\ - Convenient online submission \\ - Thorough peer review \\ - No space constraints or color figure charges \\ - Immediate publication on acceptance \\ - Inclusion in PubMed, CAS, Scopus and Google Scholar \\ - Research which is freely available for redistribution}

Submit your manuscript at www.biomedcentral.com/submit

() BioMed Central 